\title{
A validated stability indicating HPLC method for determination of sitagliptin
}

\author{
Ola Ahmed Saleh a, Aida Abd El-Sattar El-Azzouny a, \\ Hassan Youssef Aboul-Enein a,* and Amr Mohamed Badawey b \\ a Medicinal and Pharmaceutical Chemistry Department, Pharmaceutical and Drug Industries Research Division, National Research Centre, 12311 Dokki, Cairo, \\ Egypt \\ b Pharmaceutical Chemistry Department, Faculty of Pharmaceutical Sciences and Pharmaceutical Industries, Future University, 12311, Cairo, Egypt
}

*Corresponding author at: Medicinal and Pharmaceutical Chemistry Department, Pharmaceutical and Drug Industries Research Division, National Research Centre, 12311 Dokki, Cairo, Egypt.

Tel.: +20.2.33335454. Fax: +20.2.33370931. E-mail address: haboulenein@yahoo.com (H.Y. Aboul-Enein).

\section{ARTICLE INFORMATION}

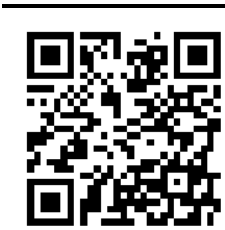

DOI: $10.5155 /$ eurjchem.5.3.497-502.1080

Received: 22 April 2014

Received in revised form: 21 May 2014

Accepted: 21 May 2014

Online: 30 September 2014

\section{KEYWORDS}

HPLC

Sitagliptin

Sitagliptin phosphate

Liquid chromatography

Stability-indicating assays

Pharmaceutical dosage form

\section{Introduction}

Sitagliptin phosphate (STG) [1-4] is 1,2,4-triazolo [4,3-a] pyrazine,7-[(3R)-3-amino-1-oxo-4-(2,4,5-trifluorophenyl) butyl]-5,6,7,8-tetra-hydro-3-(trifluoromethyl) phosphate (Figure 1). It is the first dipeptidylpeptidase-4 inhibitor to be used in the management of type 2 diabetes. It is widely used as an add-on therapy to ongoing management or as monotherapy when it is deemed necessary. It has been found to be beneficial in improving $\beta$-cell function and glycemic control. Moreover, in special circumstances like chronic kidney disease it is used with appropriate dose reductions [5].

Literature survey revealed that some LC-MS methods [6-9] were reported for the determination of sitagliptin phosphate in plasma and urine of humans, rats and dogs. Also, spectrophotometric techniques were used for the determination of sitagliptin and characterized by their simplicity, specificity and low cost $[10,11]$. In addition, some analytical methods were used for the validation and estimation of sitagliptin in bulk and pharmaceutical formulations [12-14]. This study presents a comparative determination of sitagliptin phosphate on three different stationary phases, Poroshell 120 EC-C18, Pursuit 5PFP and Chromolith Performance RP-18e column. All the validation parameters and stability-indicating study will be studied on the column, which achieves the best determination of sitagliptin phosphate in bulk and pharmaceutical formulations.

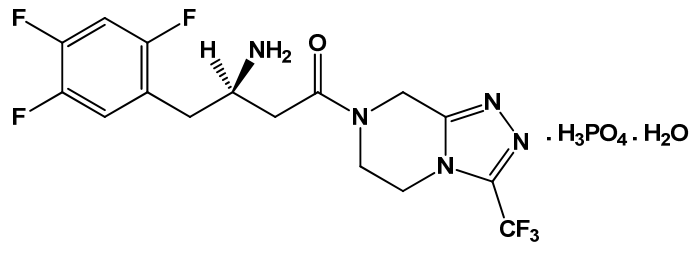

Figure 1. Sitagliptin phosphate.

\section{Experimental}

\subsection{Chemicals and reagents}

Sitagliptin phosphate standard bulk powder was obtained from Merck Sharp \& Dohme Ltd., Cramlington Northumberland and was used as received, certified to be $99.80 \%$ pure. Januvia $100 \mathrm{mg}, 50 \mathrm{mg}$ and $25 \mathrm{mg}$ (Labeled to contain $100 \mathrm{mg}, 50 \mathrm{mg}$ and $25 \mathrm{mg}$ of sitagliptin phosphate per tablet) were obtained from the Merck Sharp \& Dohme Ltd., Cramlington, UK 
(Imported by SoficoPharm, Cairo, Egypt). Methanol, triethyl amine, acetic acid were obtained from Merck (Darmstadt, Germany). All chemicals were of analytical grade. Purified HPLC grade water was obtained by reverse osmosis and filtration through a Milli-Q system (Millipore, Milfored, MA, USA) and was used as a mobile phase.

\subsection{Instrumentation and conditions}

The HPLC unit was an Agilent 1100 series apparatus equipped with a quaternary pump, a vacuum degasser, a column oven, a diode array UV-detector and HP Chemstation for LC 3D systems B.0301 [317] software. Three columns were used in this study namely $(100 \times 4.6 \mathrm{~mm}$, i.d.; particle size, 2.7 $\mu \mathrm{m})$, Pursuit 5PFP $(150 \times 4.6 \mathrm{~mm}$, i.d.; particle size, $5 \mu \mathrm{m})$ were purchased from Agilent Technologies and $(100 \times 4.6 \mathrm{~mm}$, i.d.; macropore diameter, $2 \mu \mathrm{m}$ ) was from Merck (Darmstadt, Germany). Separation was achieved using a mobile phase consisting of methanol:water:triethylamine:acetic acid 60:40: $0.1: 0.1 ; v: v: v: v)$, at a flow rate $0.5 \mathrm{~mL} / \mathrm{min}$. The column was maintained at temperature $20{ }^{\circ} \mathrm{C}$ and UV $268 \mathrm{~nm}$ and an injection volume of $5 \mu \mathrm{L}$ was used. The mobile phase was filtered through $0.45 \mu \mathrm{m}$ chromTech Nylon-66 filter and degassed in an ultrasonic bath. For analysis of forced degradation samples, the photodiode array detector was used in scan mode with a scan range of 200-500 nm.

\subsection{Statistical analysis}

Linear regression of the data was performed by using statistical package for social science (SPSS) program version 16 software (SPSS Inc., U.S.A.). The level of significance was set at $p$ $\leq 0.05$.

\subsection{Preparation of stock and standard solutions}

A stock solution of sitagliptin phosphate $(1 \mathrm{mg} / \mathrm{mL})$ was prepared in HPLC-grade methanol. The stock solution was protected from light using aluminum foil and stored for 1 week at $4{ }^{\circ} \mathrm{C}$, and was found to be stable during this period. In the HPLC assay, aliquots of the standard stock solution of sitagliptin phosphate were transferred using grade bulb pipettes into $10 \mathrm{~mL}$ volumetric flasks. The solutions were made up to volume with methanol to give final concentrations of 100 , $150,200,300,500,800$ and $1000 \mu \mathrm{g} / \mathrm{mL}$, using external standard $(1000 \mu \mathrm{g} / \mathrm{mL})$.

\subsection{Preparation of tablets for assay}

Ten tablets were weighed and ground to a fine powder. A portion of the powdered tablets equivalent to $100 \mathrm{mg}$ was accurately weighed into $100 \mathrm{~mL}-\mathrm{A}$ grade volumetric flask and $30 \mathrm{~mL}$ methanol was added. The volumetric flask was sonicated for $20 \mathrm{~min}$ to ensure complete dissolution of the sitagliptin phosphate then the solution was made up to the volume with methanol. Suitable aliquots of solution were filtered through a $0.45 \mu \mathrm{m}$ nylon filter and completed as previously mentioned under preparation of stock and standard solution for HPLC.

\subsection{Forced degradation studies of authentic sitagliptin phosphate and its tablet formulation}

In order to determine whether the proposed analytic method is stability-indicating, sitagliptin phosphate in its tablets pharmaceutical dosage form and powder was stressed under various conditions to conduct forced degradation studies. Regulatory guidance in ICH, Q2A, Q2B, Q3B and FDA 21 CFR section 211 require the development and validations of stability indicating potency assays [15].

\subsubsection{Oxidation}

Solutions for oxidation studies were prepared by dissolving $100 \mathrm{mg}$ of standard sitagliptin phosphate and powdered tablets containing an equivalent to $100 \mathrm{mg}$ of sitagliptin phosphate in methanol and $3 \% \mathrm{H}_{2} \mathrm{O}_{2}$ (20:80\%; v:v:), protected from light and stored at room temperature for 3 days.

\subsubsection{Acid degradation studies}

Solutions for acid degradation studies were achieved by refluxing $100 \mathrm{mg}$ of standard sitagliptin phosphate and powdered tablets containing an equivalent to $100 \mathrm{mg}$ of sitagliptin phosphate in $2 \mathrm{M}$ hydrochloric acid at $100{ }^{\circ} \mathrm{C}$ in an oil bath for $24 \mathrm{hr}$. The reaction mixture was neutralized with a 2.5 M sodium hydroxide and extracted with ethyl acetate, dried $\left(\mathrm{Na}_{2} \mathrm{SO}_{4}\right.$ anhydrous) and evaporated under vacuum. The residue was dissolved in methanol $(100 \mathrm{~mL})$.

\subsubsection{Alkali degradation studies}

Solutions for alkali degradation studies were performed by refluxing $100 \mathrm{mg}$ standard sitagliptin phosphate and powdered tablets containing an equivalent to $100 \mathrm{mg}$ of sitagliptin phosphate in $1 \mathrm{M}$ sodium hydroxide at $100{ }^{\circ} \mathrm{C}$ in an oil bath for $24 \mathrm{hr}$. The reaction mixture was then diluted with water and extracted with ethyl acetate, dried ( $\mathrm{Na}_{2} \mathrm{SO}_{4}$ anhydrous) and evaporated under vacuum. The residue was dissolved in methanol $(100 \mathrm{~mL})$.

\subsubsection{Neutral degradation studies}

Solutions for neutral degradation studies were prepared by dissolving $100 \mathrm{mg}$ standard sitagliptin phosphate and powdered tablets containing an equivalent to $100 \mathrm{mg}$ of sitagliptin phosphate in methanol and water $(20: 80, v: v)$, protected from light, and stored at room temperature for 3 days.

\subsubsection{Temperature stress studies}

Standard sitagliptin phosphate and its powdered tablets were exposed to dry heat $\left(90^{\circ} \mathrm{C}\right)$ in an oven for 3 days.

\subsubsection{Photostability degradation assay}

Bulk sitagliptin phosphate powder, its powdered tablets, and their methanolic solutions were exposed to light to determine the effect of irradiation on the stability of sitagliptin phosphate in the solid state and in the solution form. Approximately, $100 \mathrm{mg}$ of standard sitagliptin phosphate powders were spread on a glass dish in a layer that was less than $2 \mathrm{~mm}$ in thickness. Solutions of standard sitagliptin phosphate $(1 \mathrm{mg} / \mathrm{mL})$ were prepared in methanol. All samples for photostability testing were placed in a light cabinet (Thermolab, India) and exposed to light for $40 \mathrm{~h}$ resulting in an overall illumination $\geq 200 \mathrm{wh} / \mathrm{m}^{2}$ at $25^{\circ} \mathrm{C}$ with UV-radiation at 320-400 nm. Control samples, which were protected from light with aluminum foil, were also placed in the light cabinet and exposed concurrently following the removal from the light cabinet.

\section{Results and discussion}

\subsection{HPLC method development and optimization}

Poroshell 120 EC-C18 $(100 \times 4.6 \mathrm{~mm}$, i.d.), Pursuit 5PFP $(150 \times 4.6 \mathrm{~mm}$, i.d.) and Chromolith Performance RP-18e (100 $\times 4.6 \mathrm{~mm}$ ) columns were used for the determination of sitagliptin phosphate. 
Table 1 Comparative chromatographic and validation parameters of sitagliptin using different stationary phases

\begin{tabular}{llll} 
Table 1 Comparative chromatographic and validation parameters of sitagliptin using different stationary phases & Pursuit 5PFP Column \\
\hline Parameter & Poroshell 120 EC-C18 Column & Chromolith performance RP-18e Column & y \\
\hline Regression equation, $\mathrm{r}^{2}$ & $\mathrm{y}=0.0010 \mathrm{x}-0.008,0.999$ & $\mathrm{y}=0.0010 \mathrm{x}-0.010,0.999$ & 0.696 \\
Capacity factor $\left(\mathrm{k}^{\prime}\right)$ & 0.399 & 0.200 & 10.000 \\
Time of analysis $(\mathrm{min})$ & 10.000 & 10.000 & 5.713 \\
Retention time $(\mathrm{min})$ & 2.629 & 3.418 & 19130.824 \\
No. of theoretical plates $(\mathrm{N})$ & 8794.286 & 4673.200 & 12.75388 \\
No. of theoretical plates/mm & 87.94286 & 46.73200 & 2 \\
Tailing factor & 2.5 & 1.4 & 3 \\
Asymmetry factor & 3 & 2 & $100-1000$ \\
Linearity $(\mu \mathrm{g} / \mathrm{mL})$ & $100-1000$ & $100-1000$ & 100 \\
Sensitivity $(\mu \mathrm{g} / \mathrm{mL})$ & 100 & 100 & - \\
Precision & 1.23 & - & - \\
Repeatability & 0.99 & - & - \\
Intraday) & 0.62 & - & - \\
Intermediate precision & 1.60 & - & - \\
(Interday) & 1.20 & - & - \\
& 0.99 & - & - \\
Accuracy & 1.23 & - & - \\
& 0.82 & - & - \\
Selectivity & 0.63 & - & - \\
L.O.D. $(\mu \mathrm{g} / \mathrm{mL})$ & 1.34 & 1.20 & - \\
L.0.Q. $(\mu \mathrm{g} / \mathrm{mL})$ & 10 & - & - \\
\hline
\end{tabular}

Calibration curves, correlation coefficient, slope, intercept, capacity factor, retention time, number of theoretical plates, number of theoretical plates $/ \mathrm{mm}$, tailing factor and asymmetry factors were determined using the previously mentioned columns as shown in Table 1. It was that Poroshell 120 EC-C18 has achieved the best separation due to it has the highest number of theoretical plates/mm so it was chosen to study all the validation parameters. The method was validated for the determination of sitagliptin phosphate in bulk and in pharmaceutical dosage form. The stressed samples were initially analyzed using a mobile phase consisting of methanol: water: triethylamine:acetic acid (60:40:0.1:0.1; v:v:v:v) which achieved better separation without tailing at a flow rate of $0.5 \mathrm{~mL} / \mathrm{min}$ and UV detection at $268 \mathrm{~nm}$ using $1000 \mu \mathrm{g} / \mathrm{mL}$ sitagliptin phosphate as an external standard.

\subsection{Validation}

The method was validated with respect to parameters including linearity, limit of quantitation (LOQ), Limit of detection (LOD), precision, accuracy, selectivity and recovery using Poroshell 120 EC-C18.

\subsubsection{Linearity}

The calibration curves constructed for sitagliptin phosphate were linear over the concentration range 100-1000 $\mu \mathrm{g} / \mathrm{mL}$. Peak areas of sitagliptin phosphate were plotted versus its concentration and linear regression analysis was performed on the resultant curve.

\subsubsection{Limit of quantitation (LOQ) and limit of detection (LOD)}

The LOQ and LOD were determined based on signal to noise ratios. The LOQ was found to be $30 \mu \mathrm{g} / \mathrm{mL}$ with a resultant \%.R.S.D of $0.4 \%(n=5)$, where the LOD was found to be $10 \mu \mathrm{g} / \mathrm{mL}$.

\subsubsection{Precision}

Precision of the assay was investigated with respect to both repeatability and reproducibility. Repeatability was investigated by injecting nine replicate samples of each of the 200,400 and $600 \mu \mathrm{g} / \mathrm{mL}$ where the mean concentrations were found to be $199.81,400.23$ and 598.40 with associated relative standard deviation (\% R.S.D.) values of $1.23,0.99$ and 0.62 , respectively. Inter-day precision was assessed by injecting the same three concentrations over 3 consecutive days, resulting in mean concentrations of sitagliptin phosphate of 200.30, 400.48 and $600.22 \mu \mathrm{g} / \mathrm{mL}$ and associated \% R.S.D of 1.60, 1.20 and $0.99 \%$, respectively.

\subsubsection{Accuracy}

Accuracy of the assay was determined by interpolation of replicate $(n=6)$ peak area of three accuracy standards $(200$, 400 and $600 \mu \mathrm{g} / \mathrm{mL}$ ) from a calibration curve prepared as previously described. In each case the percent relevant error was calculated. The resultant concentration, were $199.62 \pm 0.81$ $\mu \mathrm{g} / \mathrm{mL}$, (mean \pm S.D.), $400.34 \pm 0.56 \mu \mathrm{g} / \mathrm{mL}$ and $600.52 \pm 0.41$ $\mu \mathrm{g} / \mathrm{mL}$ with percent relevant errors of $1.23,0.82$ and 0.63 , respectively.

\subsubsection{Selectivity}

The results of stress testing studies were performed on Poroshell 120 EC-C18 and showed a high degree of selectivity of this method for sitagliptin phosphate. The degradation of sitagliptin phosphate was found to be similar for both the tablets and bulk powder. Typical chromatograms obtained following the assay of pure bulk sample and stressed samples are shown in Figure 2-4.

Figure 3 showed that sitagliptin was completely degraded by hydrogen peroxide with the appearance of two degradation products at retention time 1.987 and $7.429 \mathrm{~min}$. Also, sitagliptin was partially degraded by alkaline condition and showed three degradation products at 1.921, 6.535 and 7.430 min, while the acidic condition led to partial degradation of sitagliptin with the formation of several degradation products.

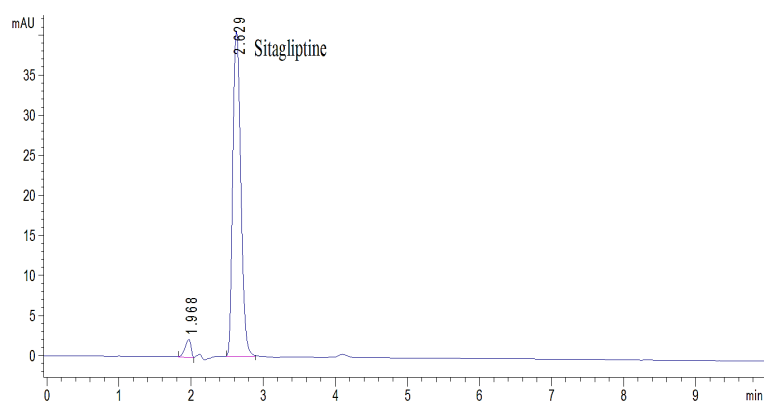

Figure 2. Typical chromatogram of sitagliptin phosphate on Poroshell 120 EC-C18 column. 

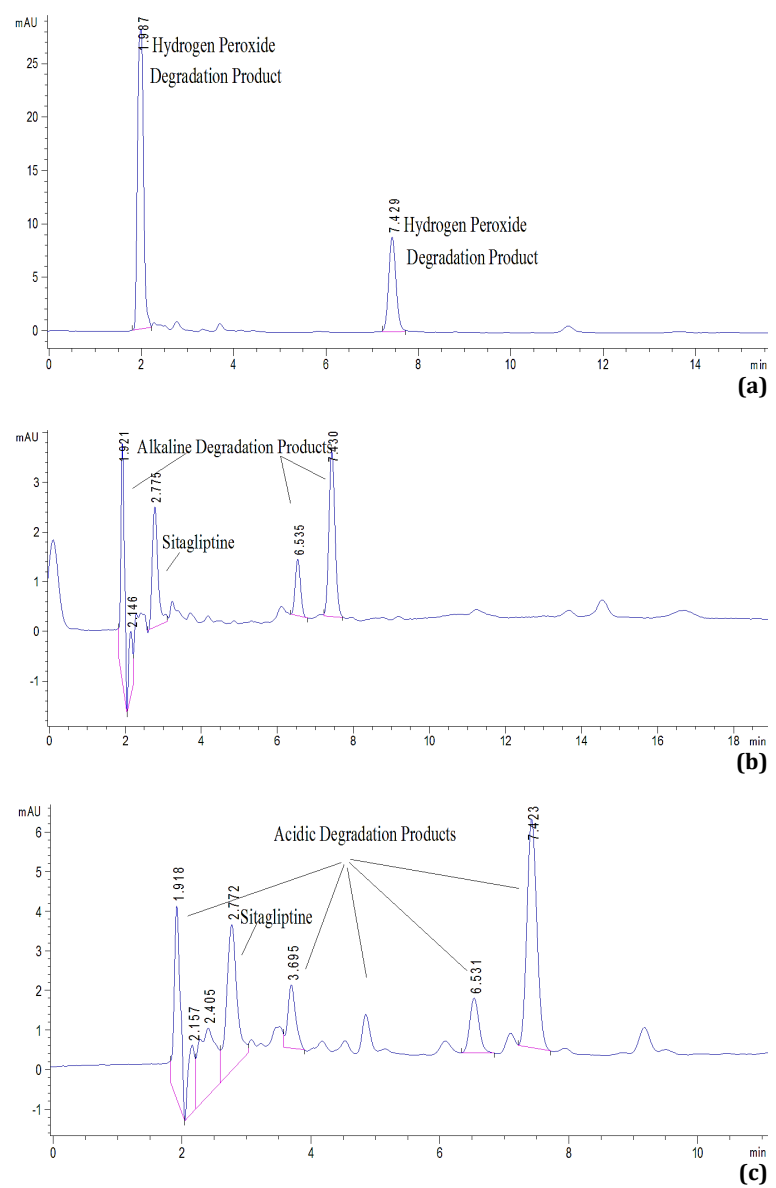

Figure 3. Degradation products of sitagliptin phosphate on Poroshell 120 EC-C18 column. (a) Hydrogen peroxide degradation products, (b) Alkaline degradation products, and (c) Acidic degradation products.

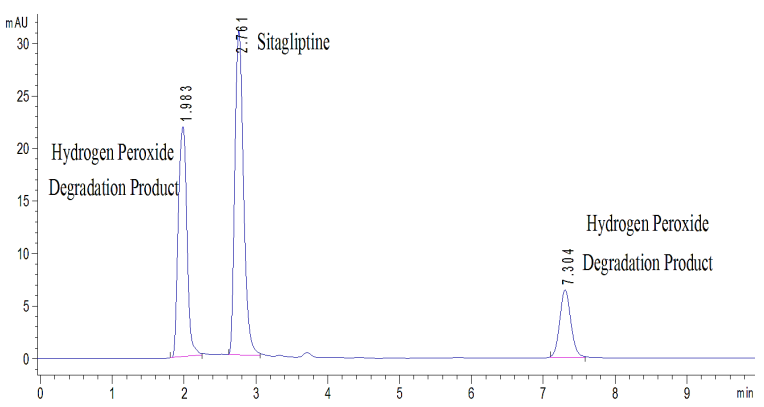

Figure 4. Lab mixture of sitagliptine and hydrogen peroxide degradation products on Poroshell 120 EC-C18 column.

\subsubsection{Recovery}

A known amount of sitagliptin phosphate standard bulk powder was added to aliquots $(n=20)$ of tablet contents, mixed, and the powder was extracted and diluted to yield a starting concentration. This solution was analyzed and the assay was repeated $(n=9)$ over 3 consecutive days to obtain intermediate precision data. The observed concentration of sitagliptin phosphate was found to be $300.00 \pm 0.42 \mu \mathrm{g} / \mathrm{mL}$ (mean \pm S.D). The resultant \% R.S.D. for this study was found to be $0.418 \%$ with a corresponding percentage recovery value of $100.44 \%$.

\subsection{Assay}

The proposed method was applied for the determination of sitagliptin phosphate in the tablet formulations. The results of these assays yielded $100.60 \%$ (\% R.S.D $=1.62 \%$ ) of expected amount of the tablets. These results indicated that the method is selective for the assay of sitagliptin phosphates without interference the excipient used in those dosage forms.

\subsection{Stability studies}

All stressed samples in both solid states and in solution forms remained colorless. No decomposition was observed in neutral medium and on exposure of sitagliptin phosphate in solid states and in solution forms to light in a photo stability chamber at room temperature. On the other hand, it was found that sitagliptin had been extensively degraded on treating with $3 \%$ hydrogen peroxide for 3 days. The retention time $R_{\mathrm{t}}$ of hydrogen peroxide degradation products of sitagliptin phosphate were 1.987 and 7.429 min. Also 76 and 28\% degradation was observed in alkaline and acidic media, respectively, as shown in Figure 3 and 4.

3.4.1. Stability-indicating method for analysis of sitagliptin phosphate in presence of its hydrogen peroxide -oxidative degraded products by HPLC

A simple HPLC method was adopted for the simultaneous determination of sitagliptin phosphate and its oxidative hydrogen peroxide degraded products in bulk powder. To optimize the proposed HPLC method, all of the experimental conditions were investigated. To optimize the mobile phases, different systems were tried for chromatographic separation of the two components by combining homogenous design and solvent polarity optimization. The best resolution was achieved using a mobile phase consisting of methanol:water:triethyl amine:acetic acid (60:40:0.1:0.1; v:v:v:v) which gave good resolution and sensitivity of all components. A linear relationship was obtained between peak area and the concentration of sitagliptin phosphate in the presence of its hydrogen peroxide oxidative degraded products in the range of $100-1000 \mu \mathrm{g} / \mathrm{mL}$. The linear regression equation was computed as:

$y=0.0010 x+0.0033 \quad r=0.9998$

where $y$ is the area under the peak, $x$ is the concentration in $\mu \mathrm{g} / \mathrm{mL}$, and $r$ is a correlation coefficient.

The results obtained by applying the HPLC procedure showed that sitagliptin phosphate can be simultaneously analyzed in the presence of its hydrogen peroxide oxidative degraded with mean recoveries of $100.05 \pm 1.399 \%$, Table 2 .

The proposed method has been applied to the assay of sitagliptin phosphate in its tablet form without any interference from the excipients. The validity of the suggested procedure was further assessed by applying the standard addition technique with mean recoveries $100.48 \pm 0.692 \%$, Table 3 .

A statistical comparison of the results obtained by the proposed HPLC method and the Clarke procedure that depends on UV spectrophotometric determinations of sitagliptin phosphate [16] in a pure drug are shown in Table 4. The calculated $t$ and $F$ values were less than the tabulated values [17], which revealed that there is no significant difference with respect to accuracy and precision determined through assay of variables. Also, some statistical analysis was studied such as linear regression parameters as shown in Table 5 and 6 .

Blind samples of pure sitagliptin phosphate of different concentrations were calculated from its regression equation. 
Table 2. Determination of pure bulk sitagliptin phosphate by HPLC.

\begin{tabular}{llll} 
Mixture no & Concentration taken $(\boldsymbol{\mu g} / \mathbf{m L})$ & Found $(\boldsymbol{\mu g} / \mathbf{m L})$ & Found $(\%)$ \\
\hline 1 & 150.00 & 151.70 & 101.13 \\
2 & 300.00 & 294.70 & 98.23 \\
3 & 500.00 & 508.70 & 101.74 \\
4 & 800.00 & 795.70 & 99.46 \\
5 & 1000.00 & 996.70 & 99.67 \\
\hline Mean \pm S.D & & & $100.05 \pm 1.399$ \\
\hline
\end{tabular}

Table 3. Application the standard addition technique to the analysis of sitagliptin phosphate by HPLC in its tablet dosage form.

\begin{tabular}{|c|c|c|c|c|}
\hline Product & Found (\%) & Pure added $(\mu \mathrm{g} / \mathrm{mL})$ & Found $(\mu \mathrm{g} / \mathrm{mL})$ & Recovery (\%) \\
\hline \multirow{5}{*}{ Januvia $100 \mathrm{mg}$ Sitagliptin phosphate/Tablet } & $100.60 \pm 1.62$ & 100.00 & 101.20 & 101.20 \\
\hline & & 200.00 & 199.10 & 99.55 \\
\hline & & 300.00 & 302.30 & 100.77 \\
\hline & & 400.00 & 403.60 & 100.90 \\
\hline & & 500.00 & 499.80 & 99.96 \\
\hline$\overline{\text { Mean } \pm \text { S.D }}$ & & & & $100.48 \pm 0.69$ \\
\hline
\end{tabular}

Table 4. Statistical analysis of the results obtained by applying the proposed UV spectrophotometric method [16] for the analysis of pure sitagliptin phosphate.

\begin{tabular}{lll}
\hline Parameter & Proposed HPLC method & UV spectrophotometric method \\
\hline Mean \pm S.D & $100.05 \pm 1.399$ & $99.88 \pm 0.899$ \\
$\mathrm{n}^{\mathrm{a}}$ & 5 & 5 \\
$\mathrm{t}$ & $0.251(2.306)^{\mathrm{b}}$ & - \\
$\mathrm{F}$ & $2.422(6.390)^{\mathrm{b}}$ & - \\
\hline
\end{tabular}

a n: Number of determinations.

$\mathrm{b}$ The values in parentheses are corresponding to the theoretical values of $\mathrm{t}$ and $\mathrm{F}$ at $(p=0.05)$.

Table 5. Linear regression data, ANOVA a of regression.

\begin{tabular}{llllll}
\hline Model & & Sum of squares & df & Mean square & F \\
\hline Mixture no: 1 & Regression & 0.720 & 1 & 0.720 & 11335.665 \\
& Residual & 0.000 & 5 & 0.000 & 0.000 b \\
& Total & 0.720 & 6 & & \\
\hline
\end{tabular}

a Dependent Variable: Area.

b Predictors: (Constant), Conc. $\mu \mathrm{g} / \mathrm{mL}$.

Table 6. Linear regression data, coefficients a.

\begin{tabular}{|c|c|c|c|c|c|c|c|c|}
\hline \multirow{2}{*}{\multicolumn{2}{|c|}{ Model }} & \multicolumn{2}{|c|}{ Unstandardized coefficients } & \multirow{2}{*}{$\begin{array}{l}\text { Standardized coefficients } \\
\text { Beta }\end{array}$} & \multirow[t]{2}{*}{$\mathbf{t}$} & \multirow[t]{2}{*}{ Sigma } & \multicolumn{2}{|c|}{ 95\% Confidence interval for B } \\
\hline & & B & Standard error & & & & Lower bound & Upper bound \\
\hline Mixture no: 1 & $\begin{array}{l}\text { Constant } \\
\text { Conc. } \mu \mathrm{g} / \mathrm{mL}\end{array}$ & $\begin{array}{l}0.003 \\
0.001\end{array}$ & $\begin{array}{l}0.005 \\
0.000\end{array}$ & 1.000 & $\begin{array}{l}0.658 \\
106.469\end{array}$ & $\begin{array}{l}0.539 \\
0.000\end{array}$ & $\begin{array}{l}-0.010 \\
0.001\end{array}$ & $\begin{array}{l}0.016 \\
0.001\end{array}$ \\
\hline
\end{tabular}

a Dependent Variable: Area.

The degree of method repeatability (intra-day) and intermediate precision (inter-days) were measured by analysing each concentration of sitagliptin phosphate four times by the proposed method in the same day and for four days, then calculating \%R.S.D. values which were 0.53 and 0.74 , respectively. The results of the proposed method showed that it is accurate, precise, specific, and rugged according to the $\%$ R.S.D. values of intra-day and inter-day determinations.

\section{Conclusion}

A validated stability-indicating HPLC analytical method has been developed for the determination of sitagliptin phosphate in pure form and in tablet dosage formulation. All the validation parameters were studied on Poroshell 120 EC-C18 column which achieved the best separation. The results of stress testing were under taken according to the international conference on harmonization (ICH) guidelines, which revealed that the studied method is selective and stability-indicating. The proposed method has been found to have the required accuracy, selectivity, sensitivity, and precision to assay sitagliptin phosphate in bulk form and in a pharmaceutical dosage form. Degradation products resulting from the stress studies and the excipients found in the tablet dosage forms did not interfere with the detection of sitagliptin phosphate which indicates that the assay are stability-indicating assay. The achieved methods are suitable for the routine analysis of sitagliptin phosphate in either bulk powder or in pharma-ceutical dosage forms. The simplicity of the applied method allows their application in quality control laboratories.

\section{Acknowledgements}

The authors are sincerely indebted and grateful to Dr. Mohamed Nabil Aboul-Enein, Professor of Pharmaceutical Chemistry, Department of Pharmaceutical and Medicinal Chemistry, National Research Centre, for his endless support, guidance and unlimited valuable advice throughout this work.

\section{References}

[1]. Herman, G. A.; Stevens, C.; Dyck, K. V.; Bergman, A.; Yi, B.; De Smet, M.; Snyder, K.; Hilliard, D.; Tanen, M.; Tanaka, W.; Wang, A. Q.; Zeng, W.; Musson, D.; Winchell, G.; Davis, M. J.; Ramael, S.; Gottesdiener, K. M.; Wagner, J. Clin. Pharmacol. Ther. 2005, 78, 675-688.

[2]. Amori, R. E.; Lau, J.; Pittas, A. G. JAMA 2007, 298, 194-206.

[3]. Rosenstok, J.; Sankoh, S.; List, J. F. Diabetes Obes. Metab. 2008, 10, 376386.

[4]. Herman, G. A.; Bergman, A.; Liu, F.; Stevens, C.; Wang, A. Q.; Zeng, W.; Chen, L.; Snyder, K.; Hilliard, D.; Tanen, M.; Tanaka, W.; Meehan, A. G.; Lasseter, K.; Dilzer, S.; Blum, R.; Wagner, J. A. J. Clin. Pharmacol. 2006, 46, 876-886.

[5]. Eligar, V. S.; Bain, S. C. Drug Des. Dev. Ther. 2013, 7, 893-903.

[6]. Vincent, S. H.; Reed, J. R.; Bergman, A. J.; Elmore, C. S.; Zhu, B.; Xu, S.; Ebel, D.; Larson, P.; Zeng, W.; Chen, L.; Dilzer, S.; Lasseter, K.; Gottesdiener, K.; Wagner, J. A.; Herman, G. A. Drug Metab. Dispos. 2007, 35, 533-538.

[7]. Wei, Z.; Donald, G. M.; Alison, L. F.; Li, C.; Michael, S. S.; Eric, J. W.; Amy, Q. W. J. Pharmaceut. Biomed. 2008, 46, 534-542.

[8]. Ramakrishna, N.; Vishwottam, K.; Koteshwara, M.; Prashanth, K Raghupathi, A.; Rajeshkumar, B. Biomed. Chromatogr. 2008, 22, 214 222.

[9]. Beconi, M. G.; Reed, J. R.; Teffera, Y.; Xia, Y. Q.; Kochansky, C. J.; Liu, D. Q.; Xu, S.; Elmore, C. S.; Ciccotto, S.; Hora, D. F.; Stearns, R. A.; Vincent S. H. Drug Metab. Dispos. 2007, 35, 525-532. 
[10]. Sekaran, C. B.; Prameela, R. Int. J. Pharm. Pharm. Sci. 2010, 2, 138-142.

[11]. Raja, T.; Rao, A. L. Int. J. Pharm. Chem. Biol. Sci. 2012, 2, 696-702.

[12]. Maste, M. M.; Parate, A. N.; Bhat, A. R. Asian J. Res. Chem. 2011, 4 , 1466-1468.

[13]. Lavanya, R.; Yunoos, Md. J. Adv. Pharm. Edu. Res. 2013, 3, 475-479.

[14]. Pathan, H.; Sreenivas, R. T.; Chandanam, S.; Ashok, R.; Swetha, K. DHR Int. Pharm. Sci. 2014, 5, 80-87.

[15]. Moffat, A. C.; Osselten, M. D.; Widdop, B. Clarke's Analysis of Drugs and Poisons in Pharmaceuticals, Body Fluids and Post Mortem Material, $3^{\text {rd }}$ Edn., Pharmaceuticals Press: London, 2004.

[16]. Clark, E. G. C. Clarke's Isolation and Identification of Drugs in Pharmaceuticals Body Fluids and post-Mortem Materials, $2^{\text {nd }}$ Edn. The Pharmaceutical Press: London, 1986.

[17]. Hinchen, J. D. Practical Statistics for Chemical Research, 1 ${ }^{\text {st }}$ Edn. Methuen and Science Paperbacks, London, 1969. 